\title{
Investigating uses and perceptions of an online collaborative workspace for the dissertation process
}

\author{
Amanda J. Rockinson-Szapkiw* \\ School of Education, Liberty University, Lynchburg, VA, USA
}

(Received 14 March 2012; final version received 2 June 2012)

\begin{abstract}
The intent of this study was to investigate 93 doctoral candidates' perceptions and use of an online collaboration workspace and content management server, Microsoft Office SharePoint, for dissertation process. All candidates were enrolled in an Ed.D. programme in the United States. Descriptive statistics demonstrate that candidates frequently use SharePoint for a variety of reasons, including assisting them in sharing and gaining information, improving the flow and organisation of the dissertation process and collaborating with their advisors mentors, in the dissertation process. Results of the multivariate analysis of variance demonstrated that doctoral students' who extensively use SharePoint have significantly higher student-to-student connectedness and student-to-advisors connectedness than doctoral students who use it moderately and on a limited basis. Additional results revealed that sense of connectedness and satisfaction are positively associated with the different features of SharePoint. Since using SharePoint to facilitate the mentorship during the dissertation process is positively associated with connectedness and satisfaction, it may positively influence completion and time to completion of a doctoral programme.
\end{abstract}

Keywords: doctoral education; computer-mediated communication; cooperative/ collaborative learning; distance education

\section{Introduction}

Over the past several decades, researchers have identified doctoral attrition as a severe problem for both students and universities (Bess 1978; Bowen and Rudenstine 1992; Hoffer et al. 2007; Terrell, Snyder, and Dringus 2009). With attrition in distance education estimated to be $10-50 \%$ higher than traditional education (Diaz 2002; Storrings 2005), doctoral attrition in online programmes is a great concern. Economic loss, time loss and resource loss are among the consequences of this problem. Diffey, an Associate Dean of the University of Notre Dame Graduate School, examined attrition for over 10 years and estimated that the reduction of doctoral attrition rate by $10 \%$ would save the university $\$ 1$ million dollars a year (Smallwood 2004). Reduction in attrition would also save doctoral students from the "tremendous" emotional pain associated with dropping out of a programme (Lovitts 1996, 2001).

\footnotetext{
*Email: aszapkiw@liberty.edu 


\section{A.J. Rockinson-Szapkiw}

Understanding reasons for doctoral attrition as well as examining specific times in which attrition occurs can help universities identify strategies to decrease it (Smallwood 2004). The National Science Foundation, Division of Science Resources Studies (1998) once identified the dissertation process as the time in which the largest amount of doctoral attrition occurs. Entering the dissertation process is often one of the most challenging experiences for a doctoral candidate as the candidate transitions from being a consumer of knowledge to a creator and scholar (Gardener 2008). Reasons for attrition during the dissertation process include but are not limited to feelings of loneliness, loss of motivation, dissatisfaction and miscommunication and problems with committee members (Lovitts 2001). Reasons for attrition in distance education are similar and include dissatisfaction (Chyung, Winiecki, and Fenner 1998), lack of engagement and community (Anderson 2004; Carnevale 2000; Rovai 2002a), lack of skills needed for self-directed learning (Nash 2005) and miscommunication among learners and educators (Moore 1993). Lack of teaching presence and interaction in the distance education environment has been linked to lack of student satisfaction and success (Shea, Li, and Pickett 2006; Swan 2003). Thus, arguably, advisors facilitation plays a critical role in students' success in distance education programmes, and, more specifically, in the completion of the dissertation process at a distance. As Connell (1985) stated, advisors mentorship "has to be seen as a form of teaching. Like other forms, it raises questions about curriculum, method, teacher/ student interaction, and educational environment" (p. 38). Thus, the importance of improving methods of facilitation in the dissertation process should not be underestimated. Improving methods of facilitation, thus improving factors correlated with persistence such as satisfaction and connectedness, has the potential to increase the number of doctoral candidates successfully completing their dissertations and, ultimately, their degrees. Tinto (1997) and Rovai (2002a) both suggest that, when advisors facilitate interaction and collaboration, they promote the development of strong community, which involves engagement, trust, dedication and, thus, persistence. Sense of connectedness in term of emotional and social connectedness supports persistence (Rovai 2002b) and positively effects student satisfaction with their course of study (Garrison, Anderson, and Archer 2000; Shea, Li, and Pickett 2006). Moreover, Terrell, Snyder, and Dringus (2009) purport that high levels of student-to-student connectedness and advisors-to-student connectedness are vital to persistence in the dissertation process.

With the rapid development of information and communication technologies, technology is playing an increasingly important role in doctoral education, and technology has been recognised as important in supporting effective facilitation in higher education. Specifically, collaborative workspaces hosted via cloud enable multiple person editing, document sharing and progress tracking; thus, potentially offer a way to facilitate candidates' work through the dissertation process. The United States-based university understudy has chosen Microsoft's SharePoint product as an internal information sharing and collaboration solution to facilitate the dissertation process. The dissertation process is a traditional process for a US' doctorate in education programme. In this study, I explore doctoral candidates' perceptions and use of an online collaboration workspace for dissertation process. Doctoral candidates' level and type of use of the workspace are examined to determine if their sense of connectedness and perceived satisfaction are influenced. 


\section{Review of the literature}

\subsection{Satisfaction, connectedness and doctoral persistence}

Two factors influence doctoral candidates' decision to drop out of a doctoral programme. These factors include personal and institutional factors (Lovitts 2005). Institutions do not have influence over candidates' personality and life circumstances; however, advisors do have influence over their interactions with doctoral candidates. Thus, they have influence over important factors that are positively associated with candidates' persistence. For example, through providing timely, critical feedback and discussion about research plans, advisors assist candidates in feeling supported and developing a sense of community (Terrell, Snyder, and Dringus 2009). Community is "a shared faith that members' needs will be met through their commitment to be together" (McMillan and Chavis 1986, p. 9). By providing support, advisors demonstrate commitment to assisting candidates with their goals. Thus, candidates perceive that their needs are being met. These strong feelings of community increase satisfaction (Bouhnik and Marcus 2006; Dede 1996; Swan 2001; Wellman 1999), and satisfaction has been shown to enhance learners' perceptions of the learning process and technology used in the process. Enhanced perceptions lead to more active engagement and participation (Laiw and Huang 2007). When individuals are engaged in a process, they are more likely to complete it. If doctoral candidates feel connected and satisfied with their dissertation experience, they will be more likely to participate actively in the process and complete their dissertations. Advisors and their mentorship are central to candidates' satisfaction and connectedness.

\subsection{Advisors facilitation and mentorship}

Prior to the implementation of formal schooling, mentorship was the primary manner in which individuals learned new skills. Individuals would work alongside an expert, and knowledge about the skill would be transmitted for the purpose of the apprentice becoming like the expert (Collins, Brown, and Newman 1989). No matter the terminology used - supervisor, advisor, chair, mentor, facilitator - mentorship from the advisors through the dissertation process is a primary reason that doctoral candidates complete their dissertations, finish their degrees and become discipline experts like the advisors (Holsinger 2008). Galbraith (2003) said, mentoring in the dissertation process is an "intricate, long-term, one-on-one relationship that goes well beyond simply providing information. True mentoring is a complex process between professor and college adult learner that supports a mutual enhancement of critically reflective and independent thinking" (p. 16) and that it includes a "series of mentormentee dialogues noted for collaborative critical thinking and planning, mutual participation in specific goal setting and decision-making, shared evaluation regarding the results of actions, and joint reflection on the worth of areas identified for progress" (p. 11). In this type of mentor relationship, the doctoral candidate receives timely, critical feedback on progress made and engages in frequent dialogue about research.

As doctoral programmes move online, advisors are no longer afforded the opportunity to sit in a local restaurant to dialogue with doctoral candidates about research. An advisor cannot simply ask the doctoral candidate to visit his or her office to review a manuscript. For online doctoral programmes, advisors are 


\section{A.J. Rockinson-Szapkiw}

challenged to leverage information and communication technologies to mentor candidates. The technologies that have been leveraged to date have been email, content management systems and discussion forums (Hew and Knapczyk 2007; Kelly et al. 2007). Most commonly, doctoral candidates and their advisors have exchanged information and documents via email. This technology poses a variety of challenges. When multiple emails with manuscript attachments are sent, it is easy to save the manuscripts in multiple locations on multiple computers. Multiple formats can easily become disorganised. Consequently, the wrong version can be reviewed. Lost emails and delayed document exchange due to the fact that only one editor can edit a document at a time has resulted in feelings of dissatisfaction and isolation (Doherty 2006; Meyer 2003). Fortunately, in an era of the collaborative web, a variety of software and technologies are available to better support file sharing, discussions, calendar sharing, task assignment and collaborative editing.

\subsection{Cloud computing and collaborative systems}

Cloud computing was a term made popular by Google's CEO, Eric Schmidt (Nelson 2009). The term has been defined in numerous ways: it has been defined as the software that "resides on an [I]nternet server run by or on behalf of the software supplier, and users get to access the features of those applications via the internet" (Venkatraman 2009, p. 16). Some say that cloud computing is a broader term referring Internet-based services and software as the service. Collaborative software systems hosted via the cloud enables individuals who are geographically separated to work towards a common goal by multiple people editing, document sharing and progress tracking. Microsoft Office SharePoint is a collaborative software system often hosted via an intranet that many businesses and university libraries have leveraged for back office organisation, project management and collaborative communication (Diffin, Chirombo, and Nangle 2010; Pace 2009). Within both of these arenas, research has begun to emerge suggesting "Microsoft's SharePoint product as internal information sharing solution that combines the best features of both intranets and cloud computing" (Diffin, Chirombo, and Nangle 2010, p. 570). Microsoft's SharePoint has been shown effective for creating a collaborative knowledge base, an information management system that is secure and accessible and streamlined communication (Atkins and Cole 2010; Diffin, Chirombo, and Nangle 2010) To a less degree, Microsoft's SharePoint has been leveraged for educational purposes within universities (Atkins and Cole 2010; Rockinson-Szapkiw 2011). Thus, limited research has been conducted. One pretest-posttest study suggested after adoption of Microsoft's SharePoint to facilitate communication and file sharing in the dissertation process that doctoral candidates' satisfaction and sense of community increased. More research is needed to understand how use of Microsoft's SharePoint in the online dissertation process influences candidates' perception of the dissertation process and advisors facilitation in the process.

\section{Purpose statement}

Thus, this study aims to examine doctoral candidates' use and perceptions of a collaborative workspace for the dissertation process. This study also aims to examine how the use of different features of the workspace influences students' perceived satisfaction and sense of connectedness. Results from this study will inform 
administrator and educators whether the adoption of SharePoint to facilitate the mentor relationship for the dissertation process is beneficial as well as provide recommendations for system implementation when adopting SharePoint site for the dissertation process. The present study was designed to address the following research questions:

(1) How do doctoral candidates use a collaborative web-based workspace during their dissertation process to collaborate with their advisors mentors?

(2) How does doctoral candidates' use of a collaborative web-based workspace influence their sense of connectedness with their peers and advisors mentor?

(3) Does actual use of the collaborative web-based workspace components predict doctoral candidates' satisfaction and connectedness?

\section{Methodology}

\subsection{Participants and setting}

The present study drew from a convenience sample of 93 doctoral candidates; the sample was selected at the convenience of the researcher and was the only known population using the identified system being studied. The participants were enrolled in an online doctorate programme at a large private university in Virginia (United States). The university enrolls approximately 60,000 residential and online students and offers over 230 programmes of study. The programme in which this study focussed was the Doctor of Education (Ed.D.). The Doctor of Education programme consists of three components, (1) the coursework, (2) the comprehensive evaluation and (3) the dissertation. The focus of the study was the doctoral dissertation process, which is completed after the successful completion of the first two components. The doctoral dissertation is the final academic requirement for the Ed.D., usually begun in the third year of study. During this process, the candidate prepares the dissertation to demonstrate his or her understanding of the literature, ability to execute research and ability to write in a scholarly fashion. The candidate writes a research proposal, defends the proposal in a proposal defense, seeks and gains Institutional Review Board (IRB) approval to ensure protection of human subjects [see the Office for Human Research Protections (OHRP) website for additional information], executes the proposed research, analyses the research data, writes a completed dissertation manuscript and defends the dissertation manuscript in a dissertation defense. A successful defense results in the degree being awarded. The volunteer response was $31.2 \%$. All volunteer participants were working towards a terminal degree in either Educational Leadership or Curriculum and Instruction. They were enrolled in the dissertation process. The participants were at different stages of the process: 47 were in the process of writing chapters one to three of their manuscripts, four were in the process of seeking IRB approval, 20 were preparing for proposal defense, nine were collecting data and 13 were writing chapters 4 and 5 . The participants rated their technology expertise at different levels. Two were considered novice, 66 were considered intermediate and 25 were considered advanced. The participants were predominately Caucasian $(n=69 ; 74 \%)$. Twentyone of the participants were African American and two of the participants were Asian. One individual choose not to disclose this information. They ranged from ages 20 to 79, where three of them were between the ages of 20 and 29, 32 of them 


\section{A.J. Rockinson-Szapkiw}

were between the ages of 30 and 39, 33 of them were between the ages of 40 and 49 and 25 were 50 or over. The sample consisted of $41(44 \%)$ males and $52(56 \%)$ females. The demographics of the sample were reflective of the national statistics on individuals pursuing doctorate degrees in education. Women constituted over two-thirds $(67 \%)$ of the population who received education doctorates, and recipients of doctoral degrees in education were primarily Caucasian (National Science Foundation 2009). The median age of recipients of doctorates of education is 41.5 years (National Science Foundation 2009). Chi-square analyses revealed that level of use and type of use of the collaborative workspace understudy was not significantly influenced $(p>0.05)$ by gender, ethnicity, computer confidence or stage in the process.

\subsection{The Dissertation Portal, the collaborative workspace}

Candidates enrolled in the dissertation process within the School of Education are provided with access to a collaborative workspace hosted via the university intranet. The workspace is called the Dissertation Portal. It was created for the purpose distributing dissertation information and facilitating collaboration and communication among candidates and dissertation committee members. The Dissertation Portal was built by one of the school of education dissertation administrators using the tools of Windows SharePoint Services, now called SharePoint Foundation. Upon implementation of the Dissertation Portal in fall 2010, advisors were provided with training via traditional and online mediums. Candidates were provided with tutorials created using Adobe Captivate; some candidates participated in on-campus training while in residence for a course. The use of the site is required for several steps in the dissertation process; however, regular use of the portal is not uniform among all candidates and committees.

The Dissertation Portal has a main site and several subsites. The central Dissertation Portal is a medium in which doctoral candidates access materials needed for the dissertation process. List and libraries include materials such as the Dissertation Handbook, manuscript templates and tutorials. A calendar lists everyone's proposal and defense dates, and discussion forum enable students to connect with one another, provide status updates, ask logistical questions and discuss research designs.

My Dissertation Portals are subsites. Each candidate has his or her own portal, My Dissertation Portal, which he or she shares with the university advisors. Each candidate's portal is secure and can only be accessed by the candidate and advisors. Each portal has a number of features.

\subsubsection{Lists}

Each portal contains several lists, including a list of links to Internet sites used for the dissertation process, a list of important contacts and a task list, which is the focus of this study. The task list contains a list of tasks that need to be completed by both the candidate and advisor during the various stages of the dissertation process. Each task has a workflow assigned to it, which helps automate the process and notifies the individuals involved of what needs to be done. For example, a "writing the proposal manuscript" task is an item on the list. When the candidate is ready for the advisors to review his or her manuscript, he sets the task to "Ready for 
advisor review." Once the advisor reviews the manuscript, he or she can mark the task as complete and assign a status, such as "Rewrite, Major revisions needed," "Approved to send to committee with minor revisions," etc. The task status is updated until the task is "completed." Tasks can also be assigned due dates and priorities. For example, after a defense in which a candidate is given approval with revisions, the candidate may be assigned the task of completing revisions in 10 days.

Classically in the dissertation process, an email-based workflow has been used. This has consisted of advisors and candidates emailing each other about what needs to be done. This classical workflow can pose obstacles and challenges such as the frustration and dissatisfaction due to forgotten or lost emails and miscommunication with advisors. The task list provides advisors and candidates with an organised workflow to keep track of what needs to be done.

\subsubsection{Dissertation timeline}

Each portal contains a shared calendar used to postprojected dissertation plans, deadlines and other important dates related to the dissertation process. Having goals set forth in writing and receiving feedback on them from advisors assists candidates in being successful with completing their dissertations (Goldstein 1994, Locke et al. 1981). Further, when candidates are informed of important dates in advisors schedules that can be included and considered in the timeline, they can plan accordingly to avoid frustrations such as submitting a manuscript for review while advisors are on vacation for 2 weeks. Increased interaction such as this can also serve to develop an increased sense of connectedness.

\subsubsection{Discussion forums}

Each portal contains a forum to postasynchronous, threaded messages. The forum can be synchronised with any Microsoft Outlook account, and alerts can be set to send emails when modifications to the forum are made. The forum enables threaded discussions in which the candidate and advisor can "post" and "reply." Discussion boards are mediums for conversing about issues or topics of interest. For example, a candidate may begin a discussion thread titled, "Research site needed." His or her post may describe the inability to gain permission from a university to conduct research and request that the advisor brainstorm about other sites to conduct research. The advisor can reply with thought and ideas, and then an asynchronous discussion can ensue between the advisor and candidate until the issue is resolved. Discussion forums enable organised, communication stored in one location. Forums are a place for interactions, and thus, potentially a place where advisor and student connectedness can be established.

\subsubsection{Document libraries (e.g. manuscript, IRB, Forms, proposal submission, etc.)}

Each portal contains several document libraries. Document libraries defined in simple terms are collection of files, and candidates and advisors can share, store or retrieve any type of file in a document library. Settings can be activated within the library on any document that allows for check-in and checkout, versioning history and alerts when the document is modified. For example, a candidate can upload a Word document to a manuscript library. Upon upload, an email alert is sent to the 


\section{A.J. Rockinson-Szapkiw}

advisor that the manuscript is ready for review. At the convenience of the advisor, he or she can access the library and check out the document and provide feedback. The checking in and out feature helps ensure that the document is not being edited simultaneously, and versioning history feature helps to keep track of all of the document versions to ensure that the most recent is being reviewed. Document libraries eliminate the feelings of frustration and dissatisfaction that can stem from lost emailed documents, delayed document exchanges and incorrect version reviews of documents (Doherty 2006; Meyer 2003).

\subsection{Procedures}

After using the Dissertation Portal for collaboration with committee members for one academic year, at the end of the spring 2011 semester, participants completed a web-based survey. The survey was administered to doctoral candidates participating in the Dissertation Seminar course during spring 2011. The survey link was located in the Dissertation Seminar Blackboard course; the course instructions asked that candidates complete the survey during the final week of the semester term. Some chairs emphasised the importance of participating in the research for improving online doctoral experience. Data from the SharePoint site usage report were collected immediately following the collection of survey data.

\subsection{Instrumentation}

The web-based survey that consisted of demographic questions, the Doctoral Connectedness Scale (Terrell, Snyder, and Dringus 2009) and researcher created questions about technology usage and satisfaction. Data about type of Dissertation Portal usage were obtained from SharePoint usage logs.

\subsubsection{Connectedness}

The Doctoral Connectedness Scale was used to assess students' connectedness to both their advisors and peers. The instrument consisted of two subscales: student-tostudent connectedness and faculty to student connectedness. Participants answered 18 items. On a 5-point Likert scale (i.e. 5=strongly agree, $4=$ agree, $3=$ neutral, $2=$ disagree and $1=$ strongly disagree), they are asked to indicate the response that best reflects their feelings about each statement. Statements included, "I feel like I can easily communicate with other students about the dissertation," and "I feel a spirit of community between the faculty and myself while I am working on my dissertation." Higher scores indicate a stronger sense of connectedness. Construct validity is sufficient, and the instrument has good reliability. Cronbach's alpha was 0.87 , and Spearman-Brown coefficient was 0.93 (Terrell, Snyder, and Dringus 2009). In the present study, Cronbach's alpha was 0.78. The subscales of faculty connectedness and student connectedness demonstrated high reliability at 0.91 and 0.81 , respectively.

\subsubsection{Satisfaction}

The survey asked one question pertaining to candidates' satisfaction with the overall dissertation process. On a 5-point Likert scale (i.e. $5=$ strongly satisfied, $4=$ satisfied, 
$3=$ neutral, 2 =dissatisfied and $1=$ strongly dissatisfied), participants were asked to

"Rate your level of overall satisfaction with the dissertation process."

\subsubsection{Self-reported level of use}

The survey asked one question pertaining to candidates' use of the Dissertation Portal. Participants were ask to, "Please classify your level of use of SharePoint throughout the semester." Participants could choose, "None," "Limited (1-3 times a month)," "Moderate (4-10 times a month)" and "Extensive (over 10 times a month)".

\subsubsection{Use and usefulness}

The survey asked two questions pertaining to usage. Participants were asked to identify the feature of the My Dissertation Portal that they found most useful and to identify what they found most useful about the Dissertation Portal. Usage data were obtained from the SharePoint site usage report. The usage report identified the places in which the participants clicked and edited information.

\subsection{Research design and analysis}

A casual comparative design and correlation design was used to examine doctoral candidates' perceptions of the Dissertation Portal for the dissertation process and to examine if candidates' amount and type of usage influenced candidates' sense of connectedness with their advisors and peers as well as their level of satisfaction with the dissertation process. Descriptive statistics were used to report information about candidates' usage and perceptions of the Dissertation Portal. A multivariate analysis of variances (MANOVA) was used to analyse whether candidates' self-reported usage of SharePoint influenced candidates' sense of connectedness. The effect size was calculated using the Eta squared statistic and interpreted based on Cohen's $d$ (1988). Multiple regression analyses were conducted to determine how well use of various components of the My Dissertation Portals predicted both candidates' satisfaction and connectedness.

\section{Results}

\subsection{Descriptive statistics}

Candidates were asked about their use of the Dissertation Portal. Of the 93 surveys, 91 participants responded to questions about use. When asked to identify the feature of their My Dissertation Portal that they found most useful, the majority of the candidates identified their libraries $(n=49)$. The second most useful feature identified was the timeline $(n=19)$. Some candidates reported that they found the following to be most helpful: helpful links $(n=5)$, the contact information list $(n=6)$, the discussion forums $(n=3)$ and the task lists and status update lists $(n=9)$. When asked about the most valuable benefit of using the Dissertation Portal, over $50 \%(n=52)$ of the candidates reported that it was beneficial in assisting them in "improving the flow and organization of the dissertation process." Five appreciated the fact that the SharePoint libraries work as a storage system that backs up their 


\section{A.J. Rockinson-Szapkiw}

dissertation work on a university server. Nine candidates found SharePoint's primary benefit as being "efficiency," that is, it allows them to save time. Nineteen participants found SharePoint's most valuable benefit "improved collaboration with the chair and committee members." Four candidates reported that the portal had no benefit or that they had not used it enough to realize its benefit.

\subsection{MANOVA}

A MANOVA was conducted to evaluate the null hypothesis that there is no difference in doctoral students' connectedness based on their self-reported monthly usage of the dissertation portal $(N=93)$. Self-reported usage was determined by students' response to the following survey question: "Please classify your level of use of SharePoint throughout the dissertation process." Optional responses included the following: Extensive, Moderate, Limited and None. These four options served as the four levels of the independent variable. Descriptive statistics disaggregated by level of SharePoint usage are shown in Table 1. Only two participants reported not using SharePoint. Due to this small cell size, the "none" level was removed for the purpose of the analysis.

For the MANOVA, preliminary assumption testing was conducted. There were no univariate and multivariate outliers. Results of evaluation of linearity and singularity were satisfactory. The assumption of normality for the extensive and the moderate groups was not found tenable for either dependent variable or the dependent variables combined; the assumption of normality for the limited group was found tenable. Multicollinearity was a concern as the relationship between the two dependent variables was significant and strong, $r=0.83, p>0.05$. However, the decision was made not to combine the variables. The research suggests that these two variable are independent of each other and both faculty-to-student and studentto-student connectedness are both important to measure in order to evaluate the effectiveness of the online environment. The assumption of the homogeneity of variance-covariance was not tenable based on the results of the Box's test, $M=65.05$, $F(6,62313,34)=10.53, p=0.00$. The results of Levine's test of equality of error provided evidence that the assumption of homogeneity of variance across groups was not tenable for student-to-student connectedness and student-to-advisors connectedness, $F(2,88)=10.91, p=0.00$ and $F(2,88)=15.29, p=0.00$, receptively. Due to assumption violations, a more conservative alpha level of 0.025 was set.

Results on the MANOVA yielded that there was a statistically significant difference between the groups on the combined dependent variables, Pillai's Trace $=0.97, F(2,87)=1544.78, p>0.01$, partial $\eta^{2}=0.97$. The observed power was 1.00 . When considering the dependent variables separately, Bonferroni adjusted, alpha level of 0.008 was used to control for a type 1 error. Analyses yielded a

Table 1. Dependent variable descriptive statistics disaggregated by level of SharePoint use.

\begin{tabular}{|c|c|c|c|c|c|c|c|c|}
\hline \multirow[b]{2}{*}{ Variable } & \multicolumn{2}{|c|}{$\begin{array}{l}\text { Extensive } \\
(n=21)\end{array}$} & \multicolumn{2}{|c|}{$\begin{array}{l}\text { Moderate } \\
(n=35)\end{array}$} & \multicolumn{2}{|c|}{$\begin{array}{l}\text { Limited } \\
(n=35)\end{array}$} & \multicolumn{2}{|c|}{$\begin{array}{c}\text { None } \\
(n=2)\end{array}$} \\
\hline & $M$ & $S D$ & $M$ & $S D$ & $M$ & $S D$ & $M$ & $S D$ \\
\hline Student connectedness & 40.52 & 4.65 & 30.71 & 11.30 & 26.91 & 7.87 & 28.00 & 14.14 \\
\hline Advisors connectedness & 44.10 & 1.51 & 37.51 & 8.50 & 35.23 & 6.02 & 38.00 & 2.83 \\
\hline
\end{tabular}


statistical significance difference among the groups for student-to-student connectedness, $p>0.01$, partial $\eta^{2}=0.26$, and student-to-faculty connectedness, $p>0.01$, partial $\eta^{2}=0.22$. Post hoc analyses revealed that doctoral students' who use the Dissertation Portal extensively have significantly higher student-to-student connectedness and student-to-faculty connectedness than both doctoral students who use it moderately and on a limited basis $(p>0.01)$. No other comparisons were significant.

\subsection{Regression analyses}

A multiple regression analysis was conducted to evaluate the null hypothesis that the predictor variables, type of actual use, does not significantly predict candidates' level of connectedness $(M=68.60, S D=17.36)$. Sixty-six $(71.7 \%)$ candidates used their libraries, $25(27.2 \%)$ did not. Sixty-four $(69.6 \%)$ candidates used their status update and task lists, 27 (29.3\%) did not. Fifty-six (60.9\%) candidates used their timelines, and $48(52.2 \%)$ used their discussion forums.

A preliminary analysis using normal probability plots of residuals and scatter diagrams of residuals versus predicted residuals was conducted; the normality assumption was tenable. An analysis of the intercorrelation among variables (see Table 2) as well as Tolerance and Variance inflation factors was used to evaluate the assumption of no multicollinearity; the assumption of no of multicollinearity was tenable. Box plots and Mahalanobis distances were used to evaluate the assumption of no extreme outliers; no extreme outliers were identified. No violations were detected.

There was significant evidence to reject null hypothesis, $R^{2}=0.21$, adj $R^{2}=0.17$, $F(4,90)=5.71, p<0.001$. The multiple correlation coefficient is 0.46 . Approximately $21 \%$ of the variance of the connectedness is accounted for by the combination of the usage variables. Table 3 shows the bivariate, partial, beta correlations of the predictor variables with the criterion variable. Task list usage $(t=2.05, p=0.04)$ and discussion forum usage $(t=2.64, p=0.01)$ were associated with candidates' connectedness. Library usage $(t=1.55, p=0.12)$ and timeline usage $(t=.45, p=0.65)$ did not significantly contribute to the prediction of the candidates' connectedness.

A second multiple regression analysis was conducted to determine if type of actual Dissertation Portal use predicted candidates' level of satisfaction with the dissertation process. Four candidates were strongly dissatisfied and four were dissatisfied. Twenty candidates were neutral. Twenty-eight candidates were satisfied, and 35 were strongly satisfied. Preliminary assumption testing for this multiple regression revealed no violation of assumptions. There was significant evidence to reject null hypothesis, $R^{2}=0.20$, adj $R^{2}=0.16, F(4,90)=5.48, p<0.001$. The multiple correlation coefficient is 0.45 . Approximately $20 \%$ of the variance of the satisfaction is accounted for by the combination of the SharePoint usage variables. Table 4 shows the bivariate, partial, beta correlations of the predictor variables with

Table 2. Intercorrelations among variables $(N=91)$.

\begin{tabular}{lcccc}
\hline Variable & Library usage & Task list usage & Timeline usage & Discussion forum usage \\
\hline Library usage & - & 0.09 & $0.37^{* *}$ & $0.31^{* *}$ \\
Task list usage & - & - & 0.45 & 0.31 \\
Timeline usage & - & - & - & $0.38^{* *}$ \\
\hline
\end{tabular}

Note: $* * p<0.01$. 


\section{A.J. Rockinson-Szapkiw}

Table 3. Contributions of predictor variables.

\begin{tabular}{lccccc}
\hline Variable & Zero-order $r$ & Partial $r$ & $\beta$ & SE B & B \\
\hline Library usage & 0.28 & 0.17 & 0.16 & 4.07 & 6.32 \\
Task list usage & 0.25 & $0.22^{*}$ & 0.20 & 3.65 & 7.46 \\
Timeline usage & 0.23 & 0.05 & 0.05 & 3.85 & 1.74 \\
Discussion forum usage & 0.37 & $0.27^{*}$ & 0.28 & 3.66 & 9.67 \\
\hline
\end{tabular}

Note: ${ }^{*} p<0.05$.

the criterion variable. Task list usage $(t=2.11, p=0.038)$ and discussion forum usage $(t=2.38, p=0.02)$ were associated with candidates' satisfaction. Library usage $(t=1.52, p=0.133)$ and timeline usage $(t=0.66, p=0.51)$ did not significantly contribute to the prediction of the candidates' satisfaction.

\section{Discussion}

Descriptive findings demonstrated that candidates frequently use of the Dissertation Portal (SharePoint), a collaborative web-based workspace, for a variety of reasons, including assisting them in sharing and gaining information, improving the flow and organisation of the process and collaborating with their advisors mentors. Microsoft SharePoint provides a centralised location where all dissertation manuscript versions and comments are stored; thus, ensuring that the most recent version is being reviewed by the advisor or worked upon by the candidate. It is a location where discussions can take place and all communications can be documented; thus, ensuring that all advisors are informed of the candidate's progress or lack of progress. SharePoint provides a place for candidates' to back up their work as well as organise the dissertation workflow. However, it is important to understand that the medium does not take the place of advisors' mentorship rather supports it. The medium will not support satisfaction and connectedness if the advisor takes a "hands off" approach to mentorship. A successful online dissertation process requires that the advisor takes responsibility and action to facilitate the process (Sinclair 2004). If SharePoint is adopted, the features and tools of SharePoint need to be actively leveraged for facilitation. University dissertation administration can encourage use of SharePoint tools by actively integrating its use into the formal dissertation process.

Study findings also demonstrated that doctoral candidates' who use SharePoint extensively have significantly higher student-to-student connectedness and studentto-faculty connectedness compared with doctoral candidates who use it moderately and on a limited basis. One plausible reason for this is that the increased interaction between advisors and candidates as well as among candidates via this technological

Table 4. Contributions of predictor variables $(N=91)$.

\begin{tabular}{lccccc}
\hline Variable & Zero-order $r$ & Partial $r$ & $\beta$ & SE B & B \\
\hline Library usage & 0.28 & 0.16 & 0.16 & 0.25 & 0.39 \\
Task list usage & 0.25 & $0.22^{*}$ & 0.21 & 0.23 & 0.48 \\
Timeline usage & 0.25 & 0.07 & 0.07 & 0.24 & 0.16 \\
Discussion forum usage & 0.35 & $0.25^{*}$ & 0.25 & 0.23 & 0.55 \\
\hline
\end{tabular}

Note: ${ }^{*} p<0.05$. 
medium lessened psychological distance and, thus, increased feelings of connectedness (Moore 1989; Saba 2000). Additional results revealed that sense of connectedness was positively associated with the usage of the Dissertation Portal (SharePoint) task list and discussion forum. This findings align with the notion that increasing dialogue increases connectedness; thus, aligning with the classical works of both Dede (1996) and Wellman (1999), which suggests that, as information exchange among learners and educators increase, so do feelings of community and connectedness. A significant positive relationship was also found between doctoral candidates' level of satisfaction and usage of the Dissertation Portal (SharePoint) task list and discussion forum. This finding supports the findings that suggest that interaction with advisors in the online environment can increase satisfaction (Bouhnik and Marcus 2006). Thus, this study provides some evidence for the adoption of a collaborative software system hosted via the cloud to support mentorship in the online dissertation process. The use of SharePoint is useful for collaboration just as collaborative technologies have been shown useful in the distance education classroom as a communication tool, a repository and a contribution tracker (Chan and van Aalst 2004; Jermann, Soller, and Lesgold 2004; Pozzi et al. 2007). When used for interaction, it supports doctoral candidates' sense of connectedness and satisfaction, two factors associated with persistence and completion of the dissertation.

It is also important to recognise that interaction at a distance can be dependent upon candidates' and advisors' comfort with the technological medium being used (Hillman, Willis, and Gunawardena 1994; Thurmond and Wamback 2004). As such, when adopting an information technology system such as SharePoint, it is important to provide both advisors and students with training opportunities to gain skills to use the system, thus, building confidence and comfort level. Advisors can be provided with training via advisors meetings or online tutorials. Candidates can also be provided with training via online tutorials. Early exposure to the system and use in course work may also be beneficial, so that students are comfortable with the system when they reach the dissertation process.

Other confounding factors may exist. Relational and personality factors were not controlled for in this study and may have influenced the findings. Poor relationships between advisors and candidates may have resulted in low use of the collaborative workspace. Further, personality of both candidates and advisors could have affected the use of the collaborative workspace. Intuitive and perceptive personalities, rather than sensitive and judging, prefer the online environment rather than the traditional environment and have a stronger preference for interacting (Daughenbaugh et al. 2002a). The personality dimension of introversion-extroversive has been associated with online satisfaction (Daughenbaugh et al. 2002b). Candidates with intuitive and perceptive personalities may have used the collaborative workspace more frequently; those with a tendency towards extroversion may have been more prone to be satisfied with the dissertation experience in general. As relational and personality factors have the potential to influence online interaction and satisfaction, examination of these factors is recommended in future research.

\section{Conclusion}

This study provides support for adopting Microsoft SharePoint, a collaborative software system hosted via the cloud, to support advisors mentorship in the online 


\section{A.J. Rockinson-Szapkiw}

dissertation process. As doctoral programmes increasingly go online, further research is needed to support and extend the findings of this study. The ability to generalise findings beyond this study is limited because of the small sample size, the discipline of focus, learner characteristics and university. Replication of this research is thus needed. As mentorship is central to the dissertation process and the technology is a tool to facilitate the mentorship, additional research to understand how advisors mentors are using SharePoint to engage and mentor students through the dissertation process is needed. Ways that advisors and candidates who are not technological shrewd cope and interact with the unfamiliar technological environment needs to be explored so that it can be better understood how they can be supported. Other variables important to examine in future studies of SharePoint may also include teacher presence, immediacy and length of time to complete the dissertation. In addition, consideration may be given to other factors that may affect use of SharePoint and a doctoral candidates' sense of connectedness and satisfaction, including technical-capabilities, demographic characteristics and stage in the dissertation process. The use of SharePoint for other educational endeavours that require student collaboration and advisors mentoring (e.g. internship courses) at a distance is also needed.

\section{References}

Anderson, T. (2004) Toward a theory of online learning. Theory and Practice of Online Learning, Athabasca University, Canada.

Atkins, L. \& Cole, C. (2010) 'Teaching tip an introduction to collaboration with SharePoint for first-year business students', Journal of Information Systems Education, vol. 21, no. 3, pp. 283-289.

Bess, J. L. (1978) 'Anticipatory socialization of graduate students', Research in Higher Education, vol. 8, pp. 289-317.

Bouhnik, D. \& Marcus, T. (2006) 'Interaction in distance-learning courses', Journal of the American Society Information Science and Technology, vol. 57, no. 3, pp. 299-305.

Bowen, W. \& Rudenstine, N. (1992) In Pursuit of the Ph.D., Princeton University Press, Princeton, NJ.

Carnevale, D. (2000) “Boot camp' helps new online students at Boise State U', The Chronicle of Higher Education, vol. 46, no. 24, pp. A48.

Chan, C. K. K. \& van Aalst, J. (2004) 'Learning, assessment, and collaboration in computersupported collaborative learning', in What We Know About CSCL and Implementing It in Higher Education, eds J. W. Strijbos, P. A. Kirschner \& R. L. Martens, Kluwer Academic Publishers, Boston, MA, pp. 87-112.

Chyung, Y., Winiecki, D. \& Fenner, J. (1998) 'A case study: increase enrolment by reducing dropout rates in adult distance education', Distance Learning '98. Proceedings of the Annual Conference on Distance Teaching and Learning, Madison, WI, pp. 97-102.

Cohen, J. (1988) Statistical power analysis for the behavioral sciences, 2nd ed, Lawrence Earlbaum Associations, Hillsdale, NJ.

Collins, A., Brown, J. S. \& Newman, S. E. (1989) 'Cognitive apprenticeship: teaching the craft of reading, writing and mathematics!', in Knowing, Learning, and Instruction: Essay in Honor of Robert Glaser, ed L. B. Resnick, Erlbaum, Hillsdale, NJ, pp. 453-494.

Connell, R. W. (1985) 'How to supervise a PhD', Vestes, vol. 2, pp. 38-41.

Daughenbaugh, R., et al. (2002a) 'Personality type and online versus in-class course satisfaction', Educause Quarterly, vol. 3, pp. 71-72. Available at: http://www.educause.edu/ ir/library/pdf/EQM02312.pdf

Daughenbaugh, R., et al. (2002b) 'Does personality type effect online versus in-class course satisfaction?', Proceedings of the Annual Mid-South Instructional Technology Conference, Murfreesboro, TN (ERIC Document Reproduction Service No. ED464631). pp. 2-12.

Dede, C. (1996) 'The evolution of distance education: emerging technologies and distributed learning', American Journal of Distance Education, vol. 10, no. 2, pp. 4-36. 
Diaz, D. P. (2002, May/June). Online drop rates revisited. The Technology Source. Retrieved from http://technologysource.org/article/online_drop_rates_revisited/.

Diffin, J., Chirombo, F. \& Nangle, D. (2010) 'Cloud collaboration: using Microsoft SharePoint as a tool to enhance access services', Journal of Library Administration, vol. 50, no. 5-6, pp. $570-580$.

Doherty, W. (2006) 'An analysis of multiple factors affecting retention in web based community college courses', Internet and Higher Education, vol. 9, pp. 245-255.

Galbraith, M. W. (2003) 'The adult education professor as mentor: a means to enhance teaching and learning, Perspectives: The New York Journal of Adult Learning, vol. 1, no. 1, pp. $9-20$.

Gardner, S. (2008) “"What's too much and what's too little?": the process of becoming an independent researcher in doctoral education', Journal of Higher Education, vol. 79, no. 3, pp. $326-350$.

Garrison, D. R., Anderson, T. \& Archer, W. (2000) 'Critical inquiry in a text-based environment: computer conferencing in higher education', The Internet and Higher Education, vol. 2, no. 2-3, pp. 87-105.

Goldstein, J. (1994) The Unshackled Organization, Productivity Press, Inc., Portland, OR.

Hew, K. F. \& Knapczyk, D. (2007) 'Analysis of Ill-Structured Problem Solving, Mentoring Functions, and Perceptions of Practicum Teachers and Mentors Toward Online Mentoring In A Field-Based Practicum', Instructional Science, vol. 35, no. 1, pp. 1-40.

Hillman, D. C., Willis, D. J. \& Gunawardena, C. N. (1994) 'Learner-interface interaction in distance education: an extension of contemporary models and strategies for parishioners', The American Journal of Distance Education, vol. 8, no. 2, pp. 30-42.

Hoffer, T. B., et al. (2007) Doctorate Recipients from United States Universities: Summary Report 2006, National Opinion Research Center, Chicago, IL.

Holsinger, J. W. (2008) 'Situational leadership applied to the dissertation process', Anatomical Sciences Education, vol. 1, no. 5, pp. 194-198. doi: 10.1002/ase.37

Jermann, P., Soller, A. \& Lesgold, A. (2004) 'Computer software support for CSCL', in Computer-Supported Collaborative Learning: Vol. 3. What We Know About CSCL and Implementing It in Higher Education, Series ed P. Dillenbourg, Vol. eds J. W. Strijbos, P. A. Kirschner \& R. L. Martens, Kluwer Academic Publishers, Boston, MA, pp. 141-166.

Kelly, P., Gale, K., Wheeler, S. \& Tucker, V. (2007) 'Take a stance: Promoting deliberate action through online postgraduate professional development', Technology, Pedagogy and Education, vol. 16, no. 2, pp. 153-176.

Laiw, S. S. \& Haung, H. M. (2007) 'Developing a collaborative e-learning system based on user's perceptions', Lecture Notes in Computer Science, vol. 4402, pp. 751-759.

Locke, E. A., et al. (1981) 'Goal setting and task performance: 1969-1980', Psychological Bulletin, vol. 90, no. 1, pp. 125-152. doi:10.1037/0033-2909.90.1.125.

Lovitts, B. E. (1996) Leaving the Ivory Tower: A Sociological Analysis of the Causes of Departure From Doctoral Study, Unpublished doctoral dissertation, University of Maryland.

Lovitts, B. E. (2001) Leaving the Ivory Tower: The Causes and Consequences of Departure From Doctoral Study, Rowman \& Littlefield, Lanham, MD.

Lovitts, B. (2005) 'Being a good course-taker is not enough: a theoretical perspective on the transition to independent research', Studies in Higher Education, vol. 30, no. 2, pp. $137-154$.

McMillan, D. W. \& Chavis, D. M. (1988) 'Sense of community: A definition and theory', American Journal of Community Psychology, vol. 14, no. 1, pp. 6-23.

Meyer, K. A. (2003) 'Face-to-face versus threaded discussions: the role of time and higherorder thinking, Journal of Asynchronous Learning Networks, vol. 7, no. 3, pp. 55-65.

Moore, M. G. (1989) 'Three types of interaction', The American Journal of Distance Education, vol. 3 , no. 2 , pp. $1-6$.

Moore, M. G. (1993) 'Theory for transactional distance', in Theoretical Principles of Distance Education, ed D. Keegan, Routledge, London, pp. 22-38.

National Science Foundation, (NSF). (2009) Doctorate Recipients From U.S. universities: Summary Report 2007-08, National Opinion Research Center, Chicago, IL.

National Science Foundation, Division of Science Resources Studies. (1998) Summary of Workshop on Graduate Student Attrition, NSF 99-314, Arlington, VA. 


\section{A.J. Rockinson-Szapkiw}

Nash, R. (2005) 'Course completion rates among distance learners: identifying possible methods to improve retention', Online Journal of Distance Learning Administration, vol. 8, no. 4. Available at: http://www.westga.edu/\%7Edistance/ojdla/winter84/ nash84.htm

Nelson, M. R. (2009) 'Building an open cloud', Science, vol. 324, no. 5935, pp. 1656-1657.

Pace, A. (2009) '21st century library systems', Journal of Library Administration, vol. 49, no. 6, pp. $641-642,650$.

Pozzi, F., et al. (2007) 'A general framework for tracking and analyzing learning processes in CSCL environments', Innovations in Education \& Teaching International Journal, vol. 44, no. 2 , pp. $169-180$.

Rockinson-Szapkiw, A. J. (2011) 'Improving doctoral candidates' persistence in the online dissertation process', in Proceedings of Global Learn Asia Pacific 2011, eds Z. Abas et al. Chesapeake, VA: AACE, pp. 1162-1166.

Rovai, A. (2002a) 'Sense of community, perceived cognitive learning, and persistence in asynchronous learning networks', Internet and Higher Education, vol. 5, no. 4, pp. 319-332.

Rovai, A. (2002b) 'Development of an instrument to measure classroom community', Internet and Higher Education, vol. 5, no. 3, pp. 197-211.

Saba, F. (2000) 'Research in distance education: a status report', International Review of Research in Open and Distance Learning, vol. 1, no. 1, pp. 1-9.

Shea, P., Li, C. \& Pickett, A. (2006) 'A study of teaching presence and student sense of learning community in fully online and web-enhanced college courses', Internet and Higher Education, vol. 9, pp. 175-190.

Sinclair, M. (2004) The Pedagogy of 'Good' PhD supervision: A National Cross-Disciplinary Investigation of PhD Supervision, Department of Education, Science and Training, A DEST-funded report, Australia.

Smallwood, S. (2004) 'Doctor dropout', The Chronicle of Higher Education, vol. 50, no. 2, pp. $120-129$.

Storrings, D. A. (2005) 'Attrition in distance education: a meta-analysis', in Instructional Design, Development and Evaluation - Dissertations and Theses. Paper 8. Available at: http://surface.syr.edu/idde_etd/8

Swan, K. (2001) 'Virtual interaction: design factors affecting student satisfaction and perceived learning in asynchronous online courses', Distance Education, vol. 22, no. 2, pp. 306-331.

Terrell, S. R., Snyder, M. M. \& Dringus, L. P. (2009) 'The development, validation, and application of the Doctoral Student Connectedness Scale', Higher Education and the Internet, vol. 12, no. 2, pp. 112-116. Available at: http://linkinghub.elsevier.com/

Thurmond, V. \& Wamback, K. (2004) 'Understanding interactions in distance education: a review of the literature', International Journal of Instructional Technology and Distance Learning, vol. 1, no. 1. Available at: http://www.itdl.org/journal/Jan_04/article02.htm

Tinto, V. (1997, Spring) 'Enhancing learning via community', The NEA Higher Education Journal, vol. 13 , no. 1 , pp. 53-59.

Venkatraman, A. (2009) 'Capture the cloud', Information World Review, vol. 255, pp. 16-17.

Wellman, B. (1999) 'The network community: an introduction to networks in the global village', in Networks in the Global Village, ed B. Wellman, Westview Press, Boulder, CO, pp. $1-47$. 